\section{Cooling Effect of Shade Trees with Different Characteristics in a Subtropical Urban Park}

\author{
Bau-Show Lin and Yann-Jou Lin ${ }^{1}$ \\ Department of Horticulture, National Taiwan University, No. 138, Sec. 4, \\ Keelung Road, Da-an District, Taipei City 106, Taiwan
}

Additional index words. foliage density, landscape, microclimate, tree selection

\begin{abstract}
The effect of shade trees on the air and surface-soil temperature reduction under the canopy was studied in a park in subtropical Taipei City, Taiwan. Ten species of trees and two species of bamboo, which had tightly clustered tall stems and spreading branches resembling trees in shape, were chosen for the study. In the summer of 2007, we measured leaf and canopy characteristics of each species. The microclimate conditions under the tree canopies and an unshaded open space were measured repeatedly at middays without precipitation. In comparison with the nearby unshaded open space, air temperatures under the canopies were 0.64 to $2.52{ }^{\circ} \mathrm{C}$ lower, whereas the surface-soil temperatures were 3.28 to $8.07{ }^{\circ} \mathrm{C}$ lower. Regression analysis revealed the relative contributions to air cooling effect by the plant's leaf color lightness, foliage density, leaf thickness, and leaf texture (surface roughness) in decreasing order. Foliage density had the greatest contribution to surface-soil cooling followed by leaf thickness, leaf texture, and leaf color lightness in that order. Regression analysis also revealed that solar radiation, wind velocity, and vapor pressure at the site had significant effects on temperature reduction attributable to shade trees or bamboo.
\end{abstract}

Plants in the urban environment have many functions such as modulating the microclimate, reducing air and noise pollution, providing a habitat for urban wildlife in addition to their aesthetic values. Landscape designers may have choices in selecting plant species for gardens or parks for general or specific purposes. In a region where there is a long, hot summer, planting trees for their shading and cooling effects is quite common. It has been suggested that trees can more or less alleviate urban heat island effect (Oke, 1989; Rosenfeld et al., 1995; Sailor, 1998; Weng and Yang, 2004). Shashua-Bar and Hoffman (2000) reported a significant cooling effect of urban small wooded sites and developed a model to predict the effect. Shade trees also affect the energy use for heating and cooling of buildings (Akbari et al., 1997; McPherson et al., 1988; Simpson and McPherson, 1998; Stec et al., 2005).

Although several studies on the cooling effect of shade trees in temperate urban areas have been reported (Dimoudi and Nikolopoulou, 2003; Hiraoka, 2005; Simpson, 2002), similar studies in tropical or subtropical areas are rare. Climate conditions and popular urban tree species in the tropics or subtropics are quite different from those in temperate regions. Shashua-Bar and Hoffman (2000, 2002) mentioned two genera of trees, Ficus

\footnotetext{
Received for publication 26 May 2009. Accepted for publication 7 Nov. 2009.

We greatly appreciate Professor Fu-Wen Liu and five reviewers for their careful reading of the manuscript and providing many useful suggestions. ${ }^{1}$ To whom reprint requests should be addressed; e-mail yannjlin@ntu.edu.tw.
}

and Poinciana, in their studies. There are many popular species of shade trees grown in subtropical Taiwan. To provide some guidance for shade tree selection in Taiwan as well as in other regions that have a similar climate, we evaluated the differences in cooling effect of 10 species of trees and two species of bamboo grown in a park in Taipei, Taiwan. We hypothesized that foliage density of trees and several tree leaf characteristics, including the color, texture, and thickness, might affect the effectiveness of cooling. In addition, background microclimate conditions, including the intensity of solar radiation, vapor pressure of ambient air, and wind velocity at the time of measuring temperature differences under the tree and in the open air, might affect the results. Analysis of variance plus post hoc Scheffé test of the data we obtained revealed significant differences in the cooling effect among various shade plants. Then, we used stepwise multiple regression analysis to analyze the contribution of each item of leaf and canopy characteristics and of background microclimate elements to the cooling effect.

Site of investigation and plant species. Da-An Forestry Park (long. 25 ${ }^{\circ} 1^{\prime} \mathrm{N}$, lat. $121^{\circ} 32^{\prime}$ E) located in subtropical Taipei City, Taiwan, was the site. The park has an area of 25.9 ha surrounded by high-density urban buildings and other structures. Trees and other tall plants were planted in groups to form an urban forest. Each selected group consisted of at least 10 trunks of the same species occupying greater than $300 \mathrm{~m}^{2}$ of land. Those plants were planted in 1994. The

\section{Materials and Methods}

ground under those tall plants as well as in open air was originally covered with Eremochloa ophiuroides grasses, but some heavily shaded areas were partially bare as a result of poor grass growth.

Ten tree species and two bamboo species were chosen for the investigation. The bamboo grew in a manner of tightly clustered tall stems with spreading branches and leaves. Therefore, each cluster resembled a tree because its shading effect was a concern and was treated as a tree in this study. In the text that follows, quoted terms "tree" and "trees" are sometimes used to include tree(s) and bamboo(s) in this article. The scientific names and common names of the 12 "trees" are listed in Table 1.

Measurements of coverage area, canopy thickness, and foliage density of each species. The plant canopy coverage area of each species forming a group was measured with a Mapping Handheld GPS Navigation System, GPSmap 60CSx (Garmin Ltd., Taipei, Taiwan). The measurer handheld the instrument and walked along the canopy edge and then took the reading. The thickness of the canopy of each species was measured from "tree" pictures taken with a Nikon D50 camera (Nikon Corp., Tokyo, Japan) while a person carried a $1-\mathrm{m}$ yardstick standing by the "tree" trunk. The foliage density of each species was estimated by obtaining the leaf area index (LAI). LAI is the ratio of area of leaves to the area of the ground under the canopy (Kumar and Kaushik, 2005). A LAI2000 Plant Canopy Analyzer (LI-COR Inc., Lincoln, NE) moved along a transect line 1.5 $m$ above the ground under the canopy of each "tree" species, taking measurements at every $3-\mathrm{m}$ point, and then reversed the course of movement taking another set of measurements in the same manner. At least 14 measurements were taken and then averaged for each species.

Description and measurement of leaf characteristics. Three characteristics, namely leaf color, leaf texture, and leaf thickness of the 12 species of plants, were examined. According to $\mathrm{Lu}$ et al. (2000), the leaves of those trees could be classified by dark green or light green color, smooth surface or rough surface, and thin or thick leaf thickness. Ten typical mature leaves were taken from each species and their thickness measured with a thickness gauge, Teclock SM-112 (Teclock, Nagano, Japan). Two readings were taken for each leaf. Twenty readings taken from 10 leaves were averaged for each species. Leaf color was measured with a Hunter Laboratory MiniScan Plus 4500L colorimeter (Hunter Laboratory, Reston, VA) for CIELAB L*, $\mathrm{a}^{*}$, and $\mathrm{b}^{*}$ values. $\mathrm{L}^{*}$ is the lightness coefficient that ranges from black $=0$ to white $=$ 100. Positive $a^{*}$ indicates a hue of red-purple and negative $\mathrm{a}^{*}$ indicates that of bluish green. The larger negative value of $a^{*}$, the greener. Positive $b^{*}$ indicates yellow and negative $b^{*}$ blue. The larger positive $b^{*}$, the more yellow. After measuring these values, chroma $\mathrm{C}^{*}$, an indicator of color intensity, was calculated as $\left(a^{* 2}+b^{* 2}\right)^{1 / 2}$ (McGuire, 1992). Leaf texture 
was examined by naked eye rather than instrumental measurement. A smooth surface had no visible trichomes on the upper leaf surface and was visualized as smooth. A rough surface had obvious trichomes or a rugose or scabrous surface.

Instrumental measurement of microclimatic conditions. WatchDog Model 2550 weather stations (Spectrum Technologies, Inc., Plainfield, IL) were set up one each at an experimental tree-shaded site and a control open space site at each measurement time. An experimental shaded site was at the center of the "tree" group of a species. The control open site was fixed at one spot on open, unshaded, grass-covered ground located nearby experimental shaded sites in the same park. The ground was flat at all measurement sites. All measurements were made at midday (1000 HR to $1400 \mathrm{HR}$ ) without precipitation in the summer (July and August) of 2007. Air temperature, relative humidity, wind velocity, and solar radiation were measured $1.5 \mathrm{~m}$ above ground, whereas surface-soil temperature was measured at a $3-\mathrm{cm}$ depth from the surface. These measurements were made with two sets of instruments operating simultaneously for 30 min each time at two paired sites, one "tree"shaded and the other corresponding open site. Each instrument took a reading every minute and the 30 readings were then averaged. The relative humidity data were later converted to vapor pressure taking account of the temperature when a measurement was made. Triplicated measurements were made for each "tree" species and a total of 36 measurements was made for 12 species. For each measurement made under a "tree," there was a corresponding measurement made at the control open site. The difference between the two corresponding measurements taken simultaneously at two sites was considered to be the temperature reduction attributable to the shade "tree." Only four pairs of measurements were made on each sunny midday and the 36 pairs of measurements were completed in 9 measuring days. The sequence of measurements of the 12 "trees" was decided at random.

Statistical analysis of the data. One-way analysis of variance by using SPSS software for Windows (Version 13.0; SPSS Inc., Chicago, IL) was adopted to test the significance of differences among 12 species in their effect of reducing air and surface-soil temperatures. Then the post hoc Scheffé test was conducted to separate the means (at $P<0.05$ ) of 12 species.

Furthermore, stepwise multiple regression analysis was conducted to obtain regression equations and to examine the relative contribution of each element of leaf characteristics (color, texture, thickness), foliage density (LAI), and background microclimate conditions (solar radiation, vapor pressure, wind velocity) to air temperature reduction $\left(\Delta T_{a}\right)$ and surface-soil temperature reduction $\left(\Delta T_{S}\right)$.

\section{Results}

Foliage densities (leaf area indexes), canopy thickness, canopy coverage areas, and leaf characteristics of the 12 species of shade 'trees'. Scientific and common names of 12 shade "trees" studied are listed in Table 1. There were big differences in the foliage density with LAI ranging from 1.40 to 6.11 (Table 1). There also were big differences in the canopy thickness, which ranged from 3.10 to $10.85 \mathrm{~m}$ (Table 1). The canopy coverage area also differed greatly from one species to another (Table 1). Although each species was planted together as a group, the number of plants in one group differed from another. Therefore, the coverage area differences among species might not directly reflect species characteristics.

Among the 12 species, four had dark green, whereas eight others had light green colored leaves according to $\mathrm{Lu}$ et al. (2000). The four species with dark green leaves had CIELAB L* values of their leaves ranging from 31.13 to 37.60 (Table 2). The remaining eight species classified as light green-colored, with one exception, i.e., Pistacia chinensis, had $\mathrm{L}^{*}$ values ranging from 38.49 to 44.57 (Table 2), higher than those of the four species with dark green leaves. Species with dark green leaves also had a tendency toward lower chroma ( $\mathrm{C}^{*}$ values) than those with light green leaves (Table 2). The relation- ships between leaf color of dark or light green and $a^{*}$ values or that and $b^{*}$ values were not obvious however.

Among the 12 species studied, seven had smooth leaves and five others had rough leaves (Table 2) according to $\mathrm{Lu}$ et al. (2000). The senior author examined leaf surfaces of these "trees" and agreed with that classification. Three species classified as having thick leaves by $\mathrm{Lu}$ et al. (2000) had leaf thickness ranging from $0.381 \mathrm{~mm}$ to $0.748 \mathrm{~mm}$ according to our measurement (Table 2). Nine others classified as having thin leaves by $\mathrm{Lu}$ et al. (2000) had leaf thicknesses ranging from 0.174 to 0.347 $\mathrm{mm}$ (Table 2).

Differences in the cooling effect of 12 species of shade 'trees'. Air temperatures at the control open site averaged $33.45{ }^{\circ} \mathrm{C}$ and ranged from 30.77 to $35.03{ }^{\circ} \mathrm{C}$ in 36 measurements. Air temperatures under the canopies of all 12 "tree" groups were lower, apparently owing to the shade effect. The results of analysis of variance and F-test revealed that there were significant differences in the magnitude of temperature reduction, which ranged from 0.64 to $2.52{ }^{\circ} \mathrm{C}$, under different "tree" groups (Table 3 ). In other words, there were quantitative differences in the cooling effect

Table 1. Names, leaf area indices, canopy thickness, and canopy coverage areas of the 12 species of shade 'trees' studied.

\begin{tabular}{|c|c|c|c|c|}
\hline Scientific name & Common name & $\begin{array}{c}\text { Leaf area } \\
\text { index }\left(\mathrm{LAI}^{\mathrm{z}}\right)\end{array}$ & $\begin{array}{c}\text { Canopy } \\
\text { thickness (m) }\end{array}$ & $\begin{array}{l}\text { Coverage } \\
\text { area }\left(\mathrm{m}^{2}\right)\end{array}$ \\
\hline$\overline{\text { Alstonia scholaris }}$ & Green maple & 2.50 & 6.46 & 522 \\
\hline Bischofia javanica & Autumn maple tree & 3.15 & 4.41 & 1573 \\
\hline Cassia fitula & Golden shower tree & 1.90 & 3.41 & 804 \\
\hline Ficus elastica & Rubber plant & 5.05 & 8.94 & 3151 \\
\hline Ficus microcarpa & India laurel fig & 6.11 & 9.04 & 2486 \\
\hline $\begin{array}{l}\text { Liquidambar } \\
\text { formosana }\end{array}$ & Sweet gum & 1.52 & 7.75 & 418 \\
\hline Pistacia chinensis & Chinese pistache & 4.44 & 7.75 & 754 \\
\hline Pterocarpus indicus & Rose wood & 2.17 & 9.04 & 933 \\
\hline Sapium sebiferum & Chinese tallow tree & 1.40 & 4.34 & 707 \\
\hline Ulmus parvifolia & Chinese elm & 4.16 & 5.60 & 1633 \\
\hline Bambusa ventricosa & Swollen bamboo & 3.00 & 3.10 & 369 \\
\hline Bambusa vulgaris & Stripe bamboo & 4.77 & 10.85 & 762 \\
\hline
\end{tabular}

${ }^{\mathrm{z}} \mathrm{LAI}$ represents the ratio of area of leaves to the area of canopy coverage.

Table 2. Leaf characteristics of the 12 species of shade 'trees' studied.

\begin{tabular}{|c|c|c|c|c|c|c|c|c|}
\hline \multirow[b]{2}{*}{ Species } & \multicolumn{5}{|c|}{ Leaf color } & \multirow[b]{2}{*}{ Leaf texture } & \multicolumn{2}{|c|}{ Leaf thickness } \\
\hline & Description & $\mathrm{L}^{* \mathrm{z}}$ & $\mathrm{a}^{* \mathrm{y}}$ & $b^{* x}$ & $\mathrm{C}^{* \mathrm{w}}$ & & Description & $(\mathrm{mm})$ \\
\hline \multicolumn{9}{|l|}{ Tree } \\
\hline A. scholaris & Dark green & $36.63^{v}$ & -9.65 & 18.12 & 20.53 & Smooth & Thick & 0.381 \\
\hline B. javanica & Dark green & 37.60 & -9.17 & 18.45 & 20.60 & Smooth & Thin & 0.347 \\
\hline C. fitula & Light green & 38.49 & -6.30 & 20.89 & 21.82 & Rough & Thin & 0.239 \\
\hline F. elastica & Dark green & 31.13 & -6.75 & 8.50 & 10.85 & Smooth & Thick & 0.748 \\
\hline F. microcarpa & Dark green & 33.28 & -8.81 & 13.21 & 15.88 & Smooth & Thick & 0.426 \\
\hline L. formosana & Light green & 40.45 & -6.56 & 19.90 & 20.95 & Rough & Thin & 0.243 \\
\hline P. chinensis & Light green & 33.69 & -8.30 & 11.54 & 14.21 & Rough & Thin & 0.193 \\
\hline P. indicus & Light green & 41.90 & -10.33 & 21.71 & 24.04 & Rough & Thin & 0.235 \\
\hline S. sebiferum & Light green & 43.30 & -12.46 & 29.17 & 31.72 & Smooth & Thin & 0.238 \\
\hline U. parvifolia & Light green & 44.57 & -7.07 & 12.62 & 14.47 & Rough & Thin & 0.308 \\
\hline \multicolumn{9}{|l|}{ Bamboo } \\
\hline B. ventricosa & Light green & 42.00 & -8.83 & 18.30 & 20.32 & Smooth & Thin & 0.174 \\
\hline B. vulgaris & Light green & 40.03 & -8.98 & 18.04 & 20.15 & Smooth & Thin & 0.178 \\
\hline
\end{tabular}

${ }^{\mathrm{z}} \mathrm{L} *$ represents the lightness of the color ranging from black $=0$ to white $=100$.

y The larger negative $\mathrm{a}^{*}$, the greener.

${ }^{\mathrm{x}}$ The larger positive $\mathrm{b}^{*}$, the more yellow.

${ }^{\mathrm{w}} \mathrm{C}^{*}$ represents the color intensity, which was calculated as $\left(\mathrm{a}^{* 2}+\mathrm{b}^{* 2}\right)^{1 / 2}$.

vEach numerical entry is the mean of 10 leaves with duplicated readings for each leaf. 
of 12 species of shade "trees." The 12 species could be separated into four groups according to their effectiveness of cooling by Scheffé test at $P<0.05$ (Table 3 ). Ulmus parvifolia and $P$. indicus were the most effective, whereas $C$. fitula, B. javanica, and $B$. ventricosa were the least effective. Seven other species falling in the middle could be further grouped into two groups with substantial overlapping (Table 3).

Soil temperatures at $3 \mathrm{~cm}$ beneath the surface of the control open site averaged $33.45{ }^{\circ} \mathrm{C}$ and ranged from 30.74 to $36.10{ }^{\circ} \mathrm{C}$ in 36 measurements. The 12 species of "trees" provided temperature reductions of the surface-soil under the canopies at even greater magnitude $\left(3.28\right.$ to $\left.8.07{ }^{\circ} \mathrm{C}\right)$ than they did that of the air. Again, the degrees of temperature reduction differed significantly under different species of "trees" (Table 3). The 12 species could be separated into seven groups by Scheffé test (at $P<0.05$ ) according to their cooling effect with $F$. elastica being the most effective followed by $U$. parvifolia and $F$. microcarpa, whereas nine other less effective species were grouped into five groups with a lot of overlapping (Table 3 ). The order of effectiveness of the 12 species in surface-soil cooling was somewhat different from that in air cooling (Table 3 ).

Relative contributions of plant and leaf characteristics to cooling effects. Stepwise regression analysis of the data of temperature reduction by shade "trees" revealed that whole tree foliage density and individual leaf color darkness (or more correctly lightness), leaf thickness, and leaf texture had significant effects on cooling the shaded air (Table 4) as well as the shaded surface-soil (Table 5). The contributions of canopy thickness and canopy coverage area were insignificant (data not shown), however. When the effects of leaf color characteristic indices $\mathrm{L}^{*}, \mathrm{a}^{*}, \mathrm{~b}^{*}$, and $\mathrm{C}^{*}$ values on the temperature reduction were compared in our test analysis (data not shown), L* value was most effective and, therefore, was chosen for further analysis and discussion. The order of relative contributions of the four tree characteristic significant elements to air-temperature reduction was leaf color lightness ( $\mathrm{L}^{*}$ value) $>$ foliage density $>$ leaf thickness $>$ leaf texture as revealed by standardized coefficient in the regression analysis (Table 4 ). The order of relative contributions to surface-soil temperature reduction was foliage density $>$ leaf thickness $>$ leaf texture $>$ leaf lightness $\left(\mathrm{L}^{*}\right.$ value) (Table 5). The effect of leaf texture difference was such that rough leaves were more effective than smooth leaves in temperature reduction.

Effects of background microclimate conditions on the temperature reduction by shade 'trees'. The intensity of solar radiation had a positive effect, whereas ambient vapor pressure and wind velocity had negative effects on the magnitude of temperature reduction of the air (Table 4) as well as of the surface-soil (Table 5) under the shade "trees." The intensity of solar radiation and wind velocity had stronger influences on the temperature reduction of shaded air than that of shaded soil as revealed by the absolute values of the standardized coefficient (Tables 4 and 5). On the other hand, ambient air vapor pressure had a stronger influence on the temperature reduction of shaded soil than that of shaded air (Tables 4 and 5).

Regression equations. The following equations for air-temperature reduction $\left(\Delta T_{a}\right)$ and surface-soil temperature reduction $\left(\Delta T_{s}\right)$ were derived from the stepwise multiple regression analysis:

$$
\begin{aligned}
\Delta \mathrm{T}_{\mathrm{a}}= & -6.969+0.114 \mathrm{~L} *+0.290 \mathrm{LAI} \\
& +1.692 \text { leaf thickness }(\mathrm{mm}) \\
& +0.214 \text { leaf texture }(\text { smooth }=0, \\
& \text { rough }=1)+1.011 \text { solar radiation } \\
& \left(\mathrm{mW} \cdot \mathrm{m}^{-2}\right)-0.072 \text { wind velocity } \\
& \left(\mathrm{km} \cdot \mathrm{h}^{-1}\right)-0.730 \text { vapor pressure } \\
& (\mathrm{kPa})
\end{aligned}
$$

$$
\begin{aligned}
\Delta \mathrm{T}_{\mathrm{S}}= & 9.186+0.655 \mathrm{LAI} \\
& +3.755 \text { leaf thickness }(\mathrm{mm}) \\
& +0.643 \text { leaf texture }(\text { smooth } \\
& =0, \text { rough }=1)+0.025 \mathrm{~L} * \\
& -3.267 \text { vapor pressure }(\mathrm{kPa}) \\
& +0.682 \text { solar radiation }\left(\mathrm{mW} \cdot \mathrm{m}^{-2}\right) \\
& -0.063 \text { wind velocity }\left(\mathrm{Km} \cdot \mathrm{h}^{-1}\right)
\end{aligned}
$$

\begin{tabular}{|c|c|c|c|}
\hline Species & $\Delta \overline{T_{a}}\left({ }^{\circ} \mathrm{C}\right)^{z}$ & Species & $\Delta \overline{T_{s}}\left({ }^{\circ} \mathrm{C}\right)^{\mathrm{z}}$ \\
\hline$\frac{1}{\text { U. parvifolia }}$ & $2.52 \mathrm{a}^{\mathrm{y}}$ & F. elastica & $8.07 \mathrm{a}$ \\
\hline P. indicus & $2.24_{\mathrm{a}}^{\mathrm{a}}$ & U. parvifolia & $6.18_{\mathrm{b}}^{\mathrm{a}}$ \\
\hline S. sebiferum & $1.81 \mathrm{~b}$ & F. microcarpa & $5.80 \mathrm{~b}$ \\
\hline F. microcarpa & $1.79 \mathrm{~b}$ & P. indicus & $5.00_{\mathrm{c}}$ \\
\hline F. elastica & $1.74_{b, c}$ & P. chinensis & $4.76_{\mathrm{c}, \mathrm{d}}$ \\
\hline P. chinensis & $1.71 \mathrm{~b}, \mathrm{c}$ & B. javanica & $4.36_{\mathrm{cd}, \mathrm{c}}$ \\
\hline B. vulgaris & $1.62 \mathrm{~b}, \mathrm{c}$ & A. scholaris & $4.14_{\mathrm{d}, \mathrm{e}, 1}$ \\
\hline A. scholaris & $1.53 \mathrm{~b}, \mathrm{c}$ & B. vulgaris & $3.83 \mathrm{e}, \mathrm{f}, \mathrm{g}$ \\
\hline L. formosana & $1.43_{\mathrm{c}}$ & B. ventricosa & $3.64_{\mathrm{e}, \mathrm{f}, \mathrm{g}}$ \\
\hline B. ventricosa & $0.92 \mathrm{~d}$ & C. fitula & $3.47 \mathrm{f,g}$ \\
\hline B. javanica & $0.77 \mathrm{~d}$ & S. sebiferum & $3.33 \mathrm{~g}$ \\
\hline C. fitula & $0.64_{\mathrm{d}}$ & L. formosana & $3.28_{\mathrm{g}}^{\mathrm{s}}$ \\
\hline Average & 1.73 & & $5.68^{\circ}$ \\
\hline $\mathrm{F}$ & 162.296 & & 353.687 \\
\hline Significance & 0.000 & & 0.000 \\
\hline
\end{tabular}

\section{Discussion}

Shade "trees" have significant cooling effects on sunny days in hot seasons in the tropics and subtropics. Twelve groups in this study provided 0.64 to $2.52{ }^{\circ} \mathrm{C}$ lower air temperature and 3.28 to $8.07{ }^{\circ} \mathrm{C}$ lower surface-soil temperature under the canopies compared with the unshaded open site (Table $3)$. Therefore, shade "trees" could make the

Table 3. Temperature reductions in the air and surface-soil under the canopies of 12 species of shade 'trees.'

${ }^{2} \Delta \overline{T_{a}}=$ mean air temperature reduction; $\Delta \overline{T_{s}}=$ mean surface-soil temperature reduction

${ }^{y}$ Column means $(\mathrm{n}=3)$ with disparate subscripts in the same column are significantly different by Scheffé test, $P<0.05$.

Table 4. Regression for the effect of cooling air temperature under shade 'trees.'

\begin{tabular}{lccr}
\hline Model & $B$ coefficient & Standardized coefficient & \multicolumn{1}{c}{$\mathrm{t}$} \\
\hline Constant & -6.969 & & $-19.088^{* * *}$ \\
Leaf color lightness $\left(\mathrm{L}^{*}\right)$ & 0.114 & 0.740 & $23.075^{* * *}$ \\
Foliage density $(\mathrm{LAI})$ & 0.290 & 0.507 & $25.690^{* * *}$ \\
Leaf thickness $(\mathrm{mm})$ & 1.692 & 0.433 & $14.217^{* * *}$ \\
Leaf texture & 0.214 & 0.127 & $6.353^{* * *}$ \\
Solar radiation $\left(\mathrm{mW} \cdot \mathrm{m}^{-2}\right)$ & 1.011 & 0.407 & $19.705^{* * *}$ \\
Wind velocity $\left(\mathrm{km} \cdot \mathrm{h}^{-1}\right)$ & -0.072 & -0.309 & $-17.615^{* * *}$ \\
Vapor pressure $(\mathrm{kPa})$ & -0.730 & -0.253 & $-10.973^{* * *}$ \\
$R^{2}=0.518$ Adjusted $R^{2}=0.516 \mathrm{~F}=299.022^{* * *}$ & & \\
\hline
\end{tabular}

${ }^{2}$ Smooth surface was treated as reference category; the other category was rough surface.

*** Significant at $P<0.001$.

Table 5. Regression for the effect of cooling surface-soil temperature under shade 'trees.'

\begin{tabular}{lccr}
\hline Model & $B$ coefficient & Standardized coefficient & \multicolumn{1}{c}{$\mathrm{t}$} \\
\hline Constant & 9.186 & & $15.195^{* * *}$ \\
Foliage density $(\mathrm{LAI})$ & 0.655 & 0.456 & $35.416^{* * *}$ \\
Leaf thickness $(\mathrm{mm})$ & 3.755 & 0.376 & $17.824^{* * *}$ \\
Leaf texture & 0.643 & 0.152 & $11.727^{\text {z*** }}$ \\
Leaf color lightness $\left(\mathrm{L}^{*}\right)$ & 0.025 & 0.066 & $3.247^{* * *}$ \\
Vapor pressure $(\mathrm{kPa})$ & -3.267 & -0.433 & $-28.505^{* * *}$ \\
Solar radiation $\left(\mathrm{mW} \cdot \mathrm{m}^{-2}\right)$ & 0.682 & 0.108 & $8.420^{* * *}$ \\
Wind velocity $\left(\mathrm{km} \cdot \mathrm{h}^{-1}\right)$ & -0.063 & -0.102 & $-9.430^{* * *}$ \\
$R^{2}=0.816$ Adjusted $R^{2}=0.816 \mathrm{~F}=1190.270 * * *$ & & \\
\hline
\end{tabular}

${ }^{\mathrm{z}}$ Smooth surface was treated as reference category; the other category was rough surface.

*** Significant at $P<0.001$. 
microenvironment more comfortable to people not only by shading off direct solar radiation at the moment, but also by providing cooler temperature. Lower soil temperature during the day also means less trapped heat energy to be dissipated into the air at night and, hence, prolonging the cooling effect further. Massive planting of shade-effective trees in a tropical or subtropical city or region may substantially reduce the air temperature day and night by this means. Shashua-Bar and Hoffman (2000) estimated that the cooling effect of a small green site would be perceivable $100 \mathrm{~m}$ away from the site.

Some "trees" had greater effect of cooing than others. The shading of $U$. parvifolia reduced air temperature by $2.52{ }^{\circ} \mathrm{C}$ but that of C. fitula only by $0.64{ }^{\circ} \mathrm{C}$ (Table 3 ). The difference was almost fourfold. Shadings of "tree" groups reduced the surface-soil temperature even more than they did the air temperature (Table 3), but the difference between the greatest $\left(8.07{ }^{\circ} \mathrm{C}\right)$ and the least $\left(3.28{ }^{\circ} \mathrm{C}\right)$ reduction was only 2.5 -fold. Although the order of effectiveness of the 12 "trees" in surface-soil cooling did not parallel that in air cooling (Table 3), the two were not completely unrelated. The top five on the list of surface-soil cooling were all within the top six on the list of air cooling (Table 3 ). It is also noted that the top three on the list of surface-soil cooling (Table 3) were also the top three species that had largest coverage areas (Table 1). Because the measuring spot of each species was near the center of the coverage area, the spot under a larger coverage area should have a shorter duration of direct solar radiation impingement each day while the incidence of radiation rotates from east to west. Therefore, the spot might have inherited more residual cooling effect of previous days than other spots under smaller canopy coverage areas.

Regression results for air cooling effect of the "trees" showed that the order of the relative contribution of "tree" characteristics was leaf color on the top followed by foliage density, leaf thickness, and leaf texture (Table 4). When leaf colors were roughly classified into two categories (dark green and light green), light green-leafed "trees" were more effective in cooling than dark greenleafed ones according to one regression analysis (data not shown). When quantitative measurements for CIELAB L* values were made and regressed, a clear relationship between the $\mathrm{L}^{*}$ and cooling effect was obtained (Table 4). The relationships between the degree of cooling and $a^{*}, b^{*}$, or chroma $C^{*}$ of the leaves were less significant (data not shown). The $\mathrm{L}^{*}$ values of green leaves of the 12 "trees" we measured covered only a narrow range from 31.13 to 44.57 , but the small differences of $\mathrm{L}^{*}$ among trees were enough to make significant differences in the cooling effect (Table 4). Lighter leaves might reflect the radiation heat more and absorb less than darker leaves.

Foliage density of the canopy as measured by LAI ranked second in importance of tree characteristics for the cooling effect of a "tree" (Table 4). LAI has been reported to affect the cooling properties of plants (Kumar and Kaushik, 2005; Takakura et al., 2000; Tanaka and Hashimoto, 2006). Larger LAI also had greater evaporation (Rey, 1999) as well as greater transpiration of leaves of the plant canopy (Granier, 1996; Rey, 1999). Both evaporation and transpiration dissipate heat. Shashua-Bar and Hoffman (2000) found that a partial shaded area (PSA) under the tree canopy was a major factor to determine cooling effect of the tree; and they used PSA in estimating the effect of trees on the contribution of direct solar radiation to air temperature variances (Shashua-Bar and Hoffman, 2002). LAI represents foliage density, which includes not only PSA, but also leaf area taking into account multilayers of leaves forming the canopy.

Leaf thickness also affects the cooling effect of trees (Table 4). When the leaf thickness was classified into two categories (thick or thin), thick-leafed "trees" had a greater cooling effect in one regression analysis (data not shown). When the leaf thickness was measured in millimeters, a significant regression was also obtained (Table 4). Another leaf characteristic that affected the degree of cooling was leaf texture. Because it is difficult to quantify leaf roughness or smoothness, we adopted the classification of Lu et al. (2000). In the regression analysis, rough leaves had a significant positive effect on cooling (Table 4). Ehleringer (1985) reported that plants with rough leaves had less absorption of solar radiation than those with smooth leaves and, therefore, would have lower heat gained onto ambient air under the canopy. The four characteristics of shade "trees" discussed are all significant in influencing the cooling effect on surface soil also (Table 5). The order of importance of these characteristics in surface-soil temperature reduction was somewhat different from that in air temperature reduction, probably as a result of the differences in the ways and means of heat gain or loss for the air and the soil.

Regression results for factors affecting the cooling effect of shade "trees" revealed that three microclimate conditions, namely solar radiation energy, wind velocity, and air vapor pressure, had significant influences on the air (Table 4) as well as on surface-soil temperature reduction (Table 5). Although the intensity of solar radiation had a positive effect, wind velocity and vapor pressure had negative effects (Tables 4 and 5). Therefore, the cooling effect of shade "trees" depends very much on the weather at the time of measurement.

Simpson (2002) described tree types such as large or small, upright or spreading, and so on, which might affect tree-shade effects. We measured the actual air temperature and surface-soil temperature reductions by the shading of 12 different species of "trees" in a park and found big differences among species. We also identified four characteristics of "trees" that influenced the effect of temperature reduction. The results might be useful in predicting the cooling effect of a tree we had not studied. It seems possible to maximize the cooling effect of shade trees by careful selection of species based on their canopy and leaf characteristics. Although our field studies were carried out in a park, the result can be applied to shade trees in the yard of a building as well.

\section{Literature Cited}

Akbari, H., K.M. Dan, B.E. Sarah, and J.W. Hanford. 1997. Peak power and cooling energy savings of shade trees. Energy Build. 25:139-148.

Dimoudi, A. and M. Nikolopoulou. 2003. Vegetation in the urban environment: Microclimatic analysis and benefits. Energy Build. 35:69-76.

Ehleringer, J. 1985. Comparative microclimatology and plant responses in encelia species from contrasting habitats. J. Arid Environ. 8:45-56.

Granier, N.A. 1996. Intra- and interannual variations of transpiration, leaf area index and radial growth of a sessile oak stand (Quercus petraea). Ann. For. Sci. 53:521-536.

Hiraoka, H. 2005. An investigation of the effect of environmental factors on the budgets of heat, water vapor, and carbon dioxide within a tree. Energy 30:281-298.

Kumar, R. and S.C. Kaushik. 2005. Performance evaluation of green roof and shading for thermal protection of buildings. Build. Environ. 40:1505-1511.

Lu, F.Y., C.X. Ou, and K.C. Lu. 2000. Trees of Taiwan. COA Press, Taipei, Taiwan [in Chinese].

McGuire, R.G. 1992. Reporting of objective color measurements. HortScience 27:1254-1255.

McPherson, E.G., L.P. Herrington, and G. Heisler 1988. Impacts of vegetation on residential heating and cooling. Energy Build. 12:41-51.

Oke, T.R. 1989. The micrometeorology of the urban forest. Philosophical Transactions of the Royal Society B 324:335-349.

Rey, J.M. 1999. Modelling potential evapotranspiration of potential vegetation. Ecol. Modell. 123:141-159.

Rosenfeld, A.H., H. Akbari, S. Bretz, B.L. Fishman, D.M. Kurn, D. Sailor, and H. Taha. 1995 Mitigation of urban heat islands: Materials, utility programs, updates. Energy Build. 22:255-265.

Sailor, D.J. 1998. Simulations of annual degree day impacts of urban vegetative augmentation. Atmos. Environ. 32:43-52.

Shashua-Bar, L. and M.E. Hoffman. 2000. Vegetation as a climatic component in the design of an urban street: An empirical model for predicting the cooling effect of urban green areas with trees. Energy Build. 31:221-235.

Shashua-Bar, L. and M.E. Hoffman. 2002. The green CTTC model for predicting the air temperature in small urban wooded sites. Build. Environ. 37:1279-1288.

Simpson, J.R. 2002. Improved estimates of treeshade effects on residential energy use. Energy Build. 34:1067-1076.

Simpson, J.R. and E.G. McPherson. 1998. Simulation of tree shade impacts on residential energy use for space conditioning in Sacramento. Atmos. Environ. 32:69-74.

Stec, W.J., A.H.C. van Paassen, and A. Maziarz. 2005. Modelling the double skin façade with plants. Energy Build. 37:419-427.

Takakura, T., S. Kitade, and E. Goto. 2000. Cooling effect of greenery cover over a building. Energy Build. 31:1-6.

Tanaka, K. and S. Hashimoto. 2006. Plant canopy effects on soil thermal and hydrological properties and soil respiration. Ecol. Modell. 196:32-44.

Weng, Q. and S. Yang. 2004. Managing the adverse thermal effects of urban development in a densely populated Chinese city. J. Environ. Manage. 70:145-156. 